\title{
Anomalous Method of Cement-Sand Ratio Evaluation in Hardened Cement-Mortar or Cement- Concrete
}

\section{Shaleeni Tiwari}

Vivekanand Global University

Deeksha Aggarwal

Vivekanand Global University

Arpit Nirvan ( $\square$ arpitnirvan7@gmail.com )

I.T.S Engineering College

\section{Surendra Kumar}

Assistant director of physics division

\section{Research Article}

Keywords: OPL, PPL, sand, pit sand, manufactured sand, river sand, mortar, concrete, density

Posted Date: January 31st, 2022

DOI: https://doi.org/10.21203/rs.3.rs-1157979/v1

License: (c) (i) This work is licensed under a Creative Commons Attribution 4.0 International License. Read Full License 


\section{Abstract}

Construction or creation is a genetic human tendency and places, pyramids, houses, villas, bridges, flyovers, etc. are living examples of this inborn tendency. Civil construction is possible through proper binding materials which can bind all the construction components together. Lime has been used for centuries for this purpose but in the modern era, Portland cement has taken its place. Portland cement is widely being used to bind bricks, stones, or other construction materials in the form of cement- mortar or cement concrete. Cement-mortar or cement -concrete is made by mixing cement in a certain ratio to fine aggregates(sand) or fine and coarse aggregates together, and this certain ratio is quite important for the durability, strength, and sustainability of any civil construction. Sometimes, civil construction gets collapsed unfortunately and the ratio of cement-sand becomes the crucial point of investigation to ascertain the cause of failure. The most used method for this purpose is the acid digestion method, which is based on an insoluble percentage of silica in the cement-mortar or cement-concrete, but this method is quite lengthy having multiple stages of filtering, drying, weighing, causing multiple sources of errors. For precision, the silica percentage is being calculated through EDX/XRF nowadays. EDX/XRF method is fast as well as precise also but requires quite a costly set up as well as quite a time consuming also in respect of proper sampling and sample preparation. The present method is almost emerged as precise as the acid digestion method but gives quicker results with fewer error sources.

\section{Full Text}

Cement has many variations based on required application but mostly masonry purpose used cement is of two types i.e., ordinary Portland cement (OPL) and pozzolana Portland cement (PPL). The difference between these two types is slight that in manufacturing PPL, pozzolana materials (fly ash, etc.) are added for additional benefits and less cost. The pozzolana materials are added in PPL cement is $20-35 \%$ weightwise, otherwise, both have similar manufacturing process. OPL has acid-soluble lime components pozzolana components also. Cement is fabricated through a firmly guided chemical combination of Al, $\mathrm{Fe}, \mathrm{Si}, \mathrm{Ca}$, and other ingredients which are shown in Figure1.

Cement-mortar is made by mixing cement with fine aggregates (sand) while cement concrete is made by mixing cement with fine as well as coarse aggregates. According to some of the studies, sand grading impacts the properties of mortar [1-4]. Finer sand grading instance requires a higher water/ cement ratio to bring off an equivalent ability of mortar [5]. Fine aggregates (sand) for construction work are called sand which comes also in many variations but mostly and widely used sand are of three types i.e., Pit sand, River sand, Manufactured sand. Pit sand is mined from the ground and has a bigger grain size comparatively. Pit sand is free from salts with grain size irregular and sharp, hence considered good for general masonry work. River sand is obtained from the river bank as the name suggests. It is also free from salts but the grain size is comparatively more regular, finer, and rounded, hence considered good for plastering. Manufactured sand is obtained by crushing acid-insoluble hard stones, that is why it is called "crasser" colloquially. It has finer as well as coarser irregular grains with sharp edges, hence it is considered a better choice from these three for strength wanting purposes like masonry, beams, and 
roofs. Properties of pure cement paste are meant to be improvised by the addition of finer nanoparticles [6]. Fine nanocrystals of $\mathrm{CaOH} 2$ and AFM are considered to be favorable for the strength of cement paste [7-9]. One of the laws that discuss the assumption of the strength of mortar is Abraham's generalization law [10] which states that mortar strength varies inversely with the water/cement ratio. Law developed to measure the strength of cement paste is stated as: -

Strength $=K 1 / K 2^{W / C}$

Where $\mathrm{K} 1, \mathrm{~K} 2$ = Constants

$\mathrm{W}=$ mass of water

$\mathrm{C}=$ mass of cement

Implementation of Abraham's law is logical to any duration between 3 and 365 days of mortar age [11].

\section{Current Study}

The current study examined an alternative method of cement-sand ratio evaluation in hardened cementmortar or cement-concrete. Sand which is used in civil construction work has to qualify some conditions as per IS (Indian Standards) to be used as construction sand out of which the most important is grain size. The construction sand should have a grain size between $0.0075 \mathrm{~mm}$ to $4.75 \mathrm{~mm}$ and should not pass through 100 BSS sieve having a mesh size of 150 microns. If some part of sand passes through 100 BSS test sieve, then it should be lesser than $15 \%$. The pit sand does not have much smaller grains than 150 microns so the sand passes in almost negligible amounts through the 100 BSS test sieve. A similar story is of the river sand but

manufactured sand has that, so it has to be ascertained by proper sieving about the grading. Cement OPL and PPL both have grain sizes smaller than 150 microns, so both easily pass through the 100 BSS test sieve. For precision, the percentage of silica in the cement-mortar and cement-concrete is being calculated through EDX/XRF nowadays. EDX/XRF method is fast as well as precise also but requires a quite costly setup as well as quite a time consuming also in respect of proper sampling and sample preparation, whereas present method is almost emerged as precise as acid digestion method but gives quicker results with fewer error sources.

\section{Procedure}

A mixture of cement and pit sand ratio 1:4 is made by proper mixing. Water is added to the mixture in the proper amount to make the proper consistency of the mortar. The mortar is placed into moulds to make blocks. Settled and hardened blocks were quenched by water for seven days and dried for the next 28 days. The block was broken after drying and a small piece of almost $100 \mathrm{gram}$ weight is taken and kept in over at 100 degrees Celsius for 5-6 hours for complete drying. The piece is weighted and noted down. This piece is placed in a beaker as such without crushing and concentrated HCL (Hydrochloric acid) is 
added to fully submerge the piece. The reaction starts abruptly. The next day the beaker containing concentrated $\mathrm{HCL}$ and the piece are tested for completion of the reaction by adding a small amount of concentrated $\mathrm{HCL}$. If reaction starts again (bubble formation) means more $\mathrm{HCL}$ is required, if not then $\mathrm{HCL}$ is sufficient. Beaker is then placed on a hot plate, setting temperature 80 degrees Celsius for 2-3 hours to make sure all the soluble components of cement get dissolved in HCL. The piece is meanwhile stroked lightly and stirred with the glass rod. By stroking and stirring the piece broke into its finer components. After the complete fissure of a piece, the whole material of the beaker is filtered. During filtration, hot distilled water washing is done multiple times to remove excess acid. The filtrate is placed with filter paper (Whatman 40) in an oven at 100 degrees Celsius for 7-8 hours for complete drying, after complete drying, the material is weighed carefully and noted down, after that the material is transferred to 100 BSS test sieve for careful sieving. The remaining material on the test sieve is weighted again carefully as well as the material passed through the test sieve and noted down. Full road map of experiment is shown in Figure 2.

\section{Formulae}

To obtain cement sand ratio following calculation is used-

Dry weight of cement- mortar piece $=$ ' $D$ '

Weight of the HCL digested and dried material = ' $d$ '

Weight of (sand) material remained above the 100 BSS test sieve after sieving = ' $W$ '

Weight of material (pozzolana) passed through 100 BSS test sieve = ' $w$ '

Weight of cement in cement mortar $=\mathrm{D}-\mathrm{W}=\mathrm{X}$

Cement sand ratio $=\mathrm{X}: \mathrm{W}$

Percentage of insoluble additives of cement $=w / X * 100$

\section{Calculations}

1. For a mixture of cement and pit sand of ratio $1: 3$

The dry weight of cement- mortar piece $=39.121$ gram

Weight of the $\mathrm{HCL}$ digested and dried material $=30.278$ gram

Weight of (sand) material remained above the 100 BSS test sieve after sieving $=28.139 \mathrm{gram}$

Weight of material (pozzolana) passed through 100 BSS test sieve $=2.139$ gram

Weight of cement in cement mortar $=39.121-28.139=10.982$ gram 
Cement sand ratio $=10.982: 30.278=1: 2.757$

Percentage of insoluble additives of cement $=2.139 / 10.982 * 100=19.477 \%$

2. For a mixture of cement and pit sand of ratio 1:4

The dry weight of cement- mortar piece $=104.478$ gram

Weight of the HCL digested and dried material $=88.3931$ gram

Weight of (sand) material remained above the 100 BSS test sieve after sieving $=83.222 \mathrm{gram}$

Weight of material (pozzolana) passed through 100 BSS test sieve $=6.193$ gram

Weight of cement in cement mortar $=104.478-83.222=21.256$ gram

Cement sand ratio $=21.256: 83.222=1: 3.915$

Percentage of insoluble additives of cement $=6.193 / 21.256 * 100=29.135 \%$

3. For a mixture of cement and pit sand of ratio 1:5

The dry weight of cement- mortar piece $=62.754$ gram

Weight of the HCL digested and dried material = 55.420 gram

Weight of (sand) material remained above the 100 BSS test sieve after sieving $=51.738 \mathrm{gram}$

Weight of material (pozzolana) passed through 100 BSS test sieve $=3.682$ gram

Weight of cement in cement mortar $=62.754-51.738=11.016$

Cement sand ratio $=11.016: 51.738=1: 4.696$

Percentage of insoluble additives of cement $=3.682 / 11.016 * 100=33.424 \%$

4. For a mixture of cement and pit sand of ratio 1:6

The dry weight of cement- mortar piece $=90.546$ gram

Weight of the HCL digested and dried material $=79.254$ gram

Weight of (sand) material remained above the 100 BSS test sieve after sieving $=78.132 \mathrm{gram}$

Weight of material (pozzolana) passed through 100 BSS test sieve $=1.222$ gram

Weight of cement in cement mortar $=90.546-78.132=12.414$ gram 
Cement sand ratio $=12.414: 78.132=1: 6.295$

Percentage of insoluble additives of cement $=1.222 / 12.414 * 100=9.843 \%$

5. For a mixture of cement and pit sand of ratio $1: 7$

The dry weight of cement- mortar piece $=98$ gram

Weight of the HCL digested and dried material $=88.872 \mathrm{gram}$

Weight of (sand) material remained above the 100 BSS test sieve after sieving $=86.178 \mathrm{gram}$

Weight of material (pozzolana) passed through 100 BSS test sieve $=2.694$ gram

Weight of cement in cement mortar $=98-86.178=11.822$ gram

Cement sand ratio $=11.822: 86.178=1: 7.289$

Percentage of insoluble additives of cement $=2.694 / 11.822 * 100=22.788 \%$

As we have taken PPL cement for our experiment so the values of insoluble additives are also in good agreement with the theoretical value as shown in Table 1.

\section{Observation Table}

Table 1 : Ratios of cement mortar

\begin{tabular}{|lllllll|}
\hline $\begin{array}{l}\text { S. } \\
\text { no. }\end{array}$ & $\begin{array}{l}\text { Cement and } \\
\text { Sand ratio }\end{array}$ & $\begin{array}{l}\text { Dry } \\
\text { weight }\end{array}$ & $\begin{array}{l}\text { Weight after } \\
\text { digestion }\end{array}$ & $\begin{array}{l}\text { Above 100 } \\
\text { BSS }\end{array}$ & $\begin{array}{l}\text { Below } 100 \\
\text { BSS }\end{array}$ & Calculation \\
\hline 1 & $1: 3$ & 39.121 & 30.278 & 28.139 & 2.139 & $1: 2.757$ \\
\hline 2 & $1: 4$ & 104.478 & 88.931 & 83.222 & 6.193 & $1: 3.915$ \\
\hline 3 & $1: 5$ & 62.754 & 55.420 & 51.788 & 3.682 & $1: 4.696$ \\
\hline 4 & $1: 6$ & 90.546 & 79.254 & 78.132 & 1.122 & $1: 6.295$ \\
\hline 5 & $1: 7$ & 98.000 & 88.872 & 86.178 & 2.694 & $1: 7.289$ \\
\hline
\end{tabular}

\section{Conclusion}

The major component of the cement is acid-soluble limestone components which give a fast reaction with acid. The lime component of the cement is the main binder element and after completely dissolving it the sand grains get free. The cement mortar or cement concrete are made on the construction sites by rough measurements volume-wise, hence the exact value or standard value do not fit here. This method gave satisfactory results with pit sand and PPL cement. This method can also be utilized for concrete. The main difference will remain in removing the coarse aggregates before weighing through proper 
sieving. The main difference will remain in removing the coarse aggregates before weighing through proper sieving. The IS states that sand should not contain a grain size finer than $0.075 \mathrm{~mm}$ and also should not contain organic material, soluble salt, or materials, etc. in the light of IS guidelines, this method can be utilized for quick and almost fair results without EDX/XRF.

\section{Methodology}

Summing over 21 papers and 5 different types of calculations of current set out work, the current study has initiated possible areas for further studies about methods of cement-sand ratio evaluation in hardened cement-mortar or cement-concrete. Findings from this paper are therefore useful because the present method is almost emerged as precise as the acid digestion method but gives quicker results with fewer error sources. With a likeness and dissimilarity in mind, future studies should focus more on how to cope up with such types of lengthy methods which have multiple stages of filtering, drying, weighing causing multiple sources of errors in the acid digestion method.

\section{References}

1. B.V.V. Reddy, A. Gupta, Influence of sand grading on the characteristics of mortars and soil-cement block masonry, Constr. Build. Mater.22.8(2008) 1614-1623.

2. G. DeSchutter, A.M. Poppe, Quantification of the water demand of sand in mortar, Constr. Build. Mater.18.7(2004)517-521.

3. M. Westerholm, B. Lagerblad, J. Silfwerbrand, E. Forsberg, Influence of fine aggregate characteristics on the rheological properties of mortars, Cem.Concr. Res.30.4(2008)274-282.

4. A. Ganaw, A. Ashour, Rheological properties of mortars prepared with differ-Ent sands, ACIMater.J.111.5(2014)561-568.

5. S.K. Lim, C.S. Tan, K.P. Chen, M.L. Lee, W.P. Lee, Effect of different sand grading on strength properties of cement grout, Constr. Build. Mater.38(2013) 348-355.

6. Qing Y. Research on the Comparison of Pozzolanic Activity between Nano SiO2 and Silica Fume. concrete 2001; 3:19-22. in Chinese.

7. Xin W, Xunyan T, Yansheng Y, Yu Z. Analysis on Toughening Mechanisms of Ceramic NanoComposites. J Ceram 2000; 2:107-11. in Chinese.

8. Xijun W, Mingwen Z. Properties and Interfacial Microstructures for Nanostructured Materials. Chin J Atomic Mol Phys 1997; 2:148-52. In Chinese.

9. Colston SL, O'Connor D, Barnes P. Functional micro-concrete: The of zeolites and inorganic nanoparticles into cement micro-structures. J Mater Sci Lett 2000; 19:1085-8.

10. L.K.A. Sear, J. Dews, B. Kite, F.C. Harris, J.F. Troy, Abrams law, air, and high water-to-cement ratios, Constr. Build. Mater.10.3(1996)221-226.

11. I. Yeh, Generalization of strength versus water-cementitious ratio relationship to age, Cem.Concr.Res.36.10(2006)1865-1873. 
Figures

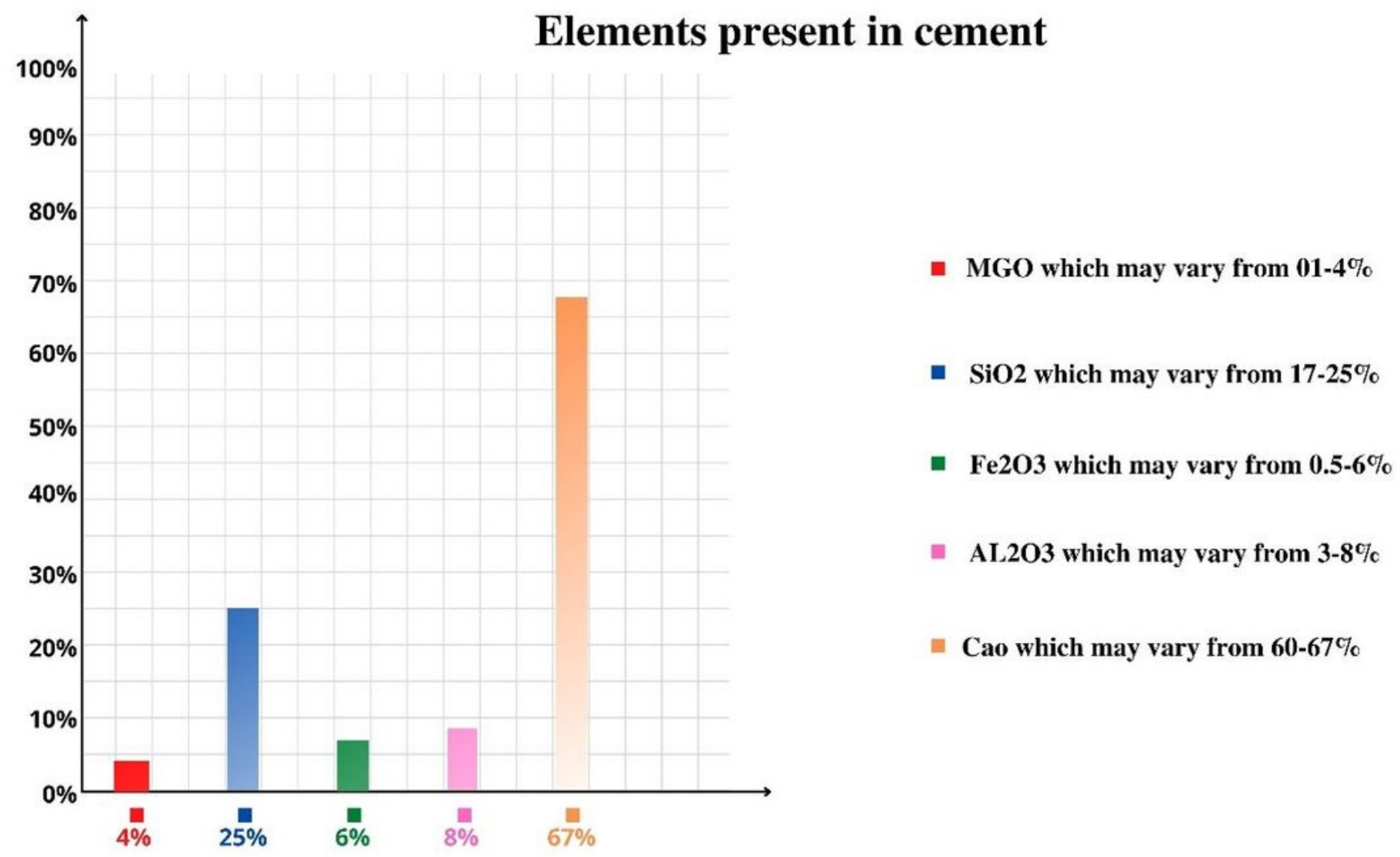

Figure 1

Elements present in Cement 


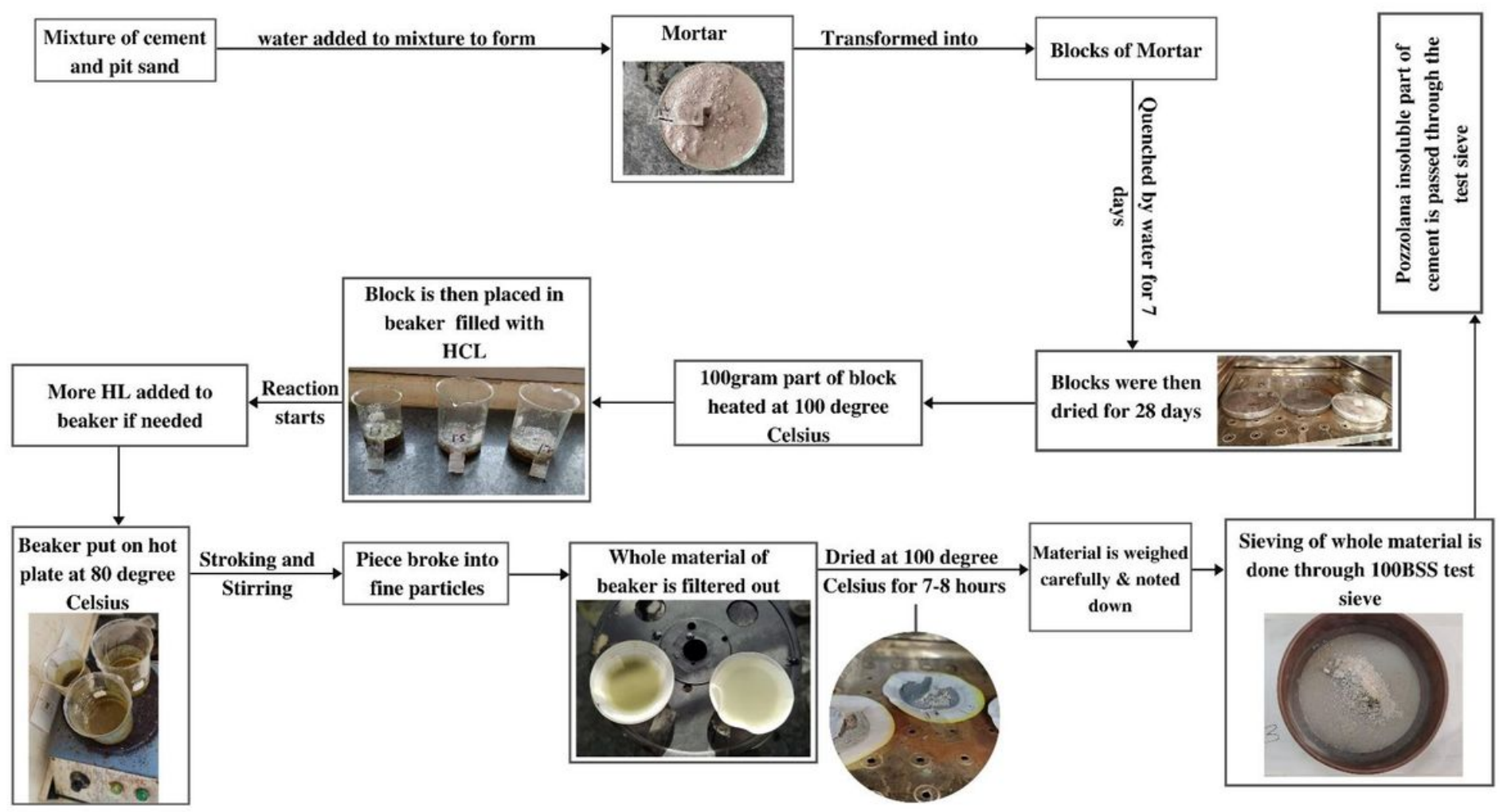

Figure 2

Full Road map of experiment 